\title{
Termite resistance of pine wood treated with nano metal fluorides
}

\author{
Shirin M. Usmani ${ }^{1,2} \cdot$ Rudy Plarre $^{2} \cdot$ Thomas Hübert $^{2} \cdot$ Erhard Kemnitz $^{1}[$
}

Received: 5 September 2019 / Published online: 21 March 2020

(c) The Author(s) 2020

\begin{abstract}
Fluorides are well-known as wood preservatives. One of the limitations of fluoride-based wood preservatives is their high leachability. Alternative to current fluoride salts such as $\mathrm{NaF}$ used in wood protection are low water-soluble fluorides. However, impregnation of low water-soluble fluorides into wood poses a challenge. To address this challenge, low water-soluble fluorides like calcium fluoride $\left(\mathrm{CaF}_{2}\right)$ and magnesium fluoride $\left(\mathrm{MgF}_{2}\right)$ were synthesized as nanoparticles via the fluorolytic sol-gel synthesis and then impregnated into wood specimens. In this study, the toxicity of nano metal fluorides was assessed by termite mortality, mass loss and visual analysis of treated specimens after eight weeks of exposure to termites, Coptotermes formosanus. Nano metal fluorides with sol concentrations of $0.5 \mathrm{M}$ and higher were found to be effective against termites resulting in $100 \%$ termite mortality and significantly inhibited termite feeding. Among the formulations tested, the least damage was found for specimens treated with combinations of $\mathrm{CaF}_{2}$ and $\mathrm{MgF}_{2}$ with an average mass loss less than $1 \%$ and visual rating of " 1 ". These results demonstrate the efficacy of low water-soluble nano metal fluorides to protect wood from termite attack.
\end{abstract}

\section{Introduction}

Termites cause significant structural damage to timber resulting in high economic losses (Pimentel et al. 2005). The invasive Formosan subterranean termite species Coptotermes formosanus, originating from China and Taiwan, has been successful in spreading to southern parts of the United States such as Florida (Chouvenc et al. 2016). Globally, the estimated economic costs from damage to goods and services due to $C$. formosanus was found to be $>$ US $\$ 30.2$ billion per year (Bradshaw et al. 2016). These costs are predicted to rise as the population of $C$. formosanus is expected to increase by $15-20 \%$, with the warming of the environment due to climate change (Buczkowski and Bertelsmeier 2017). Thus, there are ongoing research efforts to find effective wood preservatives and wood modification technologies to control the consequent damage to timber products from the spread of $C$. formosanus.

Erhard Kemnitz

erhard.kemnitz@chemie.hu-berlin.de

1 Department of Chemistry, Humboldt-Universität zu Berlin, Brook-Taylor Str. 2, 12489 Berlin, Germany

2 Bundesanstalt für Materialforschung und -prüfung, Unter den Eichen 87, 12205 Berlin, Germany
Wood modification techniques such as acetylation and furfurylation have been evaluated for their resistance to termites. Acetylated radiata pine (both leached and unleached) in EN 117 tests was found to be durable against Reticulitermes banyulensis resulting in mass loss lower than $3 \%$ (Gascón-Garrido et al. 2013). However, acetylated wood was not durable against $C$. fomosanus in a forced feeding test as even $20 \%$ acetylated larch resulted in a mass loss of 4.2\% (Imamura and Nishimoto 1986). Besides wood modification treatments, current termiticides available on the market contain active ingredients such as bifenthrin, cypermethrin, fipronil, and permethrin (Xie et al. 2013). Although effective, some of these ingredients may be toxic to human health and environment. Fipronil poisoning was reported to cause seizures, while permethrin was found to be toxic to aquatic organisms (Weston et al. 2005; Dhang 2011). An alternative to commercial termiticides are nanoparticles as their smaller size allows for improved penetration into wood (Evans et al. 2008; Taghiyari 2015). Recently, several studies have reported on the efficacy provided by the reduction in size of commercial biocidal actives like copper, boron or zinc (Clausen et al. 2011; Civardi et al. 2015; Ibáñez et al. 2019). In the form of nanoparticles, they were tested for their efficacy against termites (Kartal et al. 2009; Mantanis et al. 2014; Terzi et al. 2016; Lykidis et al. 2018). In a four week no-choice test, unleached southern yellow pine wood treated 
with nanoboron had lower mass loss than those treated with nanocopper and nanozinc (Kartal et al. 2009). In addition, unleached nanoboron-treated specimens resulted in $100 \%$ termite mortality (Kartal et al. 2009). Another study tested black pine wood treated with nano formulations of zinc oxide, zinc borate and copper oxide against $C$. formosanus (Mantanis et al. 2014). In this three week no-choice test, nanozinc borate treated wood had mass loss lower than specimens treated with nanozinc and nanocopper (Mantanis et al. 2014). Another wood preservative that could be studied for their biocidal efficacy in the form of nanoparticles are fluorides. There are several studies on the efficacy of $\mathrm{NaF}$, but no study has reported on termite resistance using nano metal fluorides.

One of the advantages of fluoride in wood preservatives is that they are effective in low concentrations (Freitag and Morrell 2005). A study on dry wood and subterranean termites found that $\mathrm{NaF}$ was more effective compared to disodium octaborate tetrahydrate (DOT) as it led to lower weight losses (Kartal et al. 2019). Concentration of $1 \% \mathrm{NaF}$ in particleboard (unleached) resulted in a mass loss of $2.3 \%$ after three weeks of exposure against $C$. formosanus (Tascioglu et al. 2017). However, the termite resistance was lost when the NaF-treated particleboard was leached. Another study reported on field efficacy of $\mathrm{NaF}$ treatment against the subterranean termites Reticulitermes flaviceps (Pan et al. 2015). A choice test done with $0.057 \%$ (w/w) NaF-treated wood inhibited attack from $R$. flaviceps (Pan et al. 2015). The research also reported that a concentration of $0.1 \%(\mathrm{w} / \mathrm{w})$ would protect timber from wood-degrading organisms. However, a follow-up study by the same research group concluded that more than $90 \%$ of fluoride from the NaF-treated blocks was leached into the surrounding soil (Pan and Wang 2015). Thus, the studies show that there is evidence of the efficacy of fluoride against termites, however, there is a need to improve its resistance against leaching.

The high leaching susceptibility of $\mathrm{NaF}$ is expected because of its high water solubility of $40 \mathrm{~g} / \mathrm{L}$ (Roark 1926). Therefore, in the past, fluoride was combined with co-biocides to reduce its leaching and increase the biocide efficacy. Mixture of fluorine-chromium-arsenic was found to be toxic to three termite species, Nasutitermes exitosus, Coptotermes acinaciformis, and Coptotermes lacteus (Gay and Schulz 1965). However, awareness of environmental and health risks associated with chromium (Cr) and arsenic (As) has led to their restricted application in wood preservation. Without these co-biocides it becomes challenging to use approved fluoride compounds in wood protection products for outdoor application. This is one of the reasons for the decline in use of fluoride compounds in wood preservation. A potential way to overcome this challenge of high leachability is to test metal fluorides $\left(\mathrm{MF}_{2}\right)$ with low water solubility such as calcium fluoride $\left(\mathrm{CaF}_{2}\right)$ and magnesium fluoride $\left(\mathrm{MgF}_{2}\right)$, but it is difficult to impregnate wood with crystalline low water-soluble fluorides. A way to overcome this limitation is to synthesize low water-soluble fluorides in the form of nanoparticles.

Nano metal fluorides are increasingly accessible since the fluorolytic sol gel synthesis was reported in 2003 (Kemnitz et al. 2003). Based on this synthetic accessibility, nano metal fluorides have been applied to anti-reflective coatings, bio-medicine and bio-plastics (Sun and Chow 2008; Krahl et al. 2016; Mahn and Kemnitz 2019). The homodispersed nanoparticles have been characterized by X-ray diffraction (XRD), transmission electron microscopy (TEM) and dynamic light scattering (DLS) (Usmani et al. 2018). The mean particle size distribution of these nanoparticles was below $25 \mathrm{~nm}$. It was shown that wood can be successfully impregnated with these nano metal fluoride particles. The distribution of these nano metal fluorides in cross-cut sections of treated wood was confirmed with scanning electron microscopy (Usmani et al. 2018). The average retention of $\mathrm{MgF}_{2}$ and $\mathrm{CaF}_{2}$ in wood specimens was 5 and $6 \%$, respectively (Usmani et al. 2018). More importantly, it was found that wood treated with nano metal fluorides had average mass loss of only $2 \%$ when attacked by brown-rot fungi, Coniophora puteana. Thus, it was shown that nanoscopic homodispersed $\mathrm{MgF}_{2}$ and $\mathrm{CaF}_{2}$ synthesized via the fluorolytic sol-gel synthesis can be successfully used for timber treatment against $C$. puteana (Usmani et al. 2018). Consequently, the following study reports on biocide efficacy of nano metal fluorides against termites, Coptotermes formosanus. Here, two different formulations of $\mathrm{CaF}_{2}$ were evaluated, one in ethylene glycol and another one in lactic acid. In addition to ethylene glycol, lactic acid as a solvent was tested as it is known to be biodegradable and compostable (Garlotta 2001). Thus, in the present study, low water-soluble fluorides $\mathrm{MgF}_{2}$ and $\mathrm{CaF}_{2}$ synthesized as nanoparticles were investigated for their efficacy against the subterranean termites, C. formosanus.

\section{Materials and methods}

\subsection{Test chemicals}

Sols of $\mathrm{CaF}_{2}$ and $\mathrm{MgF}_{2}$ were synthesized using calcium oxide, calcium lactate and magnesium ethoxide as precursors, followed by fluorination with HF as reported earlier (Usmani et al. 2018). The sols were synthesized with ethylene glycol as solvent. A combination of $\mathrm{CaF}_{2}$ and $\mathrm{MgF}_{2}$ was also synthesized in ethylene glycol. In addition, another formulation of $\mathrm{CaF}_{2}$ sol was synthesized in lactic acid (Mahn and Kemnitz 2019). A 0.1 M NaF solution was also prepared for impregnation into wood specimens for comparison. 


\subsection{Treatment}

Wood samples of dimensions $15 \mathrm{~mm}$ x $25 \mathrm{~mm}$ x $50 \mathrm{~mm}$ (radial $\mathrm{x}$ tangential $\mathrm{x}$ longitudinal) were prepared from Scots pine sapwood (Pinus sylvestris). Sols of $\mathrm{MgF}_{2}$ and $\mathrm{CaF}_{2}$ were diluted with ethanol to prepare the solutions at their respective concentration for impregnation of wood. For better penetration of the solutions into the wood, the samples were oven-dried and evacuated at $0.1-0.4 \mathrm{kPa}$ for $1 \mathrm{~h}$ prior to impregnation. After $1 \mathrm{~h}$, the solutions were introduced into the vacuum chamber and then the specimens were soaked in it for $2 \mathrm{~h}$ at ambient pressure and $20-23{ }^{\circ} \mathrm{C}$. After impregnation, the specimens were weighed and conditioned for 4 weeks at $20-23{ }^{\circ} \mathrm{C}$ and $65 \%$ relative humidity to achieve moisture equilibrium.

\subsection{Termite resistance test}

The tests against termite species, $C$. formosanus were performed in accordance with EN 117 (2012). The number of termites for each experimental setup was 250 workers and 30 soldiers. After 8 weeks, the test specimens were removed and termite mortality was determined. The specimens were dried at $103{ }^{\circ} \mathrm{C}$ for $18 \mathrm{~h}$ and then weighed to record their final mass. These specimens were also visually examined and rated according to the assessment scheme for classifying termite attack according to EN 117. Based on the visual assessment and according to EN 350 (2016), the treated specimens were assigned to durability classes ("Durable" if the visual rating was 0 or 1, "Moderately Durable" if less than $50 \%$ test specimens had a visual rating of 3 or 4 , and "Not Durable" if more than $50 \%$ had a visual rating of 3 or $4)$.

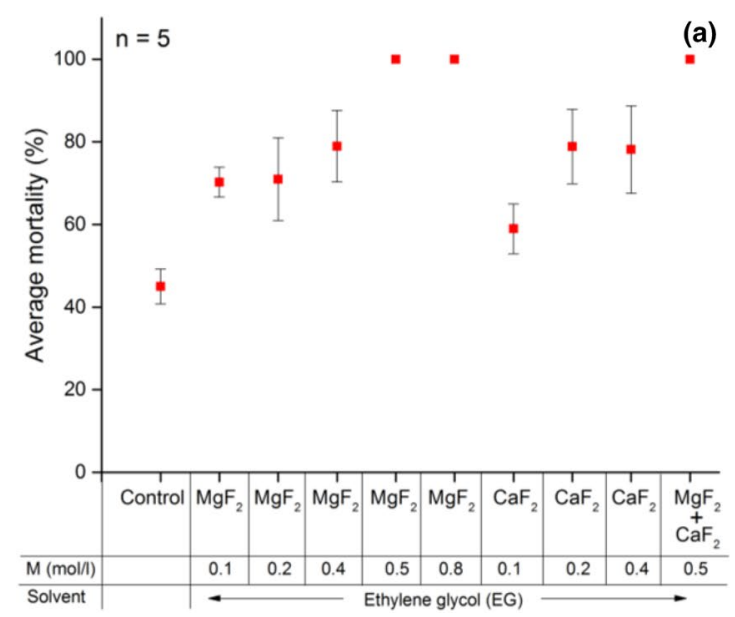

\section{Results and discussion}

The following results are separated into two sections based on the solvents used for synthesis of the respective sols. $\mathrm{MgF}_{2}$ sol was synthesized with ethylene glycol as solvent. Two sols of $\mathrm{CaF}_{2}$ were synthesized, one in ethylene glycol and another one in lactic acid. Combinations of $\mathrm{MgF}_{2}$ and $\mathrm{CaF}_{2}$ were also tested for efficacy in different formulations. The first formulation was the combination of $\mathrm{MgF}_{2}$ and $\mathrm{CaF}_{2}$ synthesized as a single sol in ethylene glycol. The second was the combination of separately synthesized sols of $\mathrm{MgF}_{2}$ in ethylene glycol and $\mathrm{CaF}_{2}$ in lactic acid. For comparison, $\mathrm{NaF}$ in $\mathrm{H}_{2} \mathrm{O}$ as solvent was also tested.

Figure 1(a) and (b) present average termite mortality caused by respective treatment of test specimens. Termite mortality in control specimens in both series (Fig. 1a, b) was less than $50 \%$, which is important for the overall validity of the EN 117 test. Additionally, termite mortality was significantly higher for almost all treated specimens compared to control specimens ( $\mathrm{p}$ value $<0.01$ ), except for specimens treated with $0.1 \mathrm{M} \mathrm{CaF}_{2}$ which had a $\mathrm{p}$ value of $0.02 \mathrm{com}$ pared to control specimens.

In Fig. 1a, the termite mortality due to $\mathrm{MgF}_{2}$-treated specimens was similar for concentrations below $0.5 \mathrm{M}$ but did not reach $100 \%$. Higher concentrations of 0.5 and $0.8 \mathrm{M} \mathrm{MgF}_{2}$ resulted in $100 \%$ termite mortality. Termite mortalities caused by $\mathrm{CaF}_{2}$ treatment in concentrations ranging from 0.1 to $0.4 \mathrm{M}$ were similar. Again, termite mortality was lowest at $0.1 \mathrm{M} \mathrm{CaF}_{2}$, while with higher concentrations of 0.2 and $0.4 \mathrm{M}$, the termite mortalities increased but did not reach $100 \%$. A higher concentration of $0.8 \mathrm{M}$ of $\mathrm{CaF}_{2}$ was assumed to be more effective than a lower concentration of $0.5 \mathrm{M} \mathrm{CaF}_{2}$, because the solubility

Fig. 1 Termite mortality due to treated specimens a nano metal fluorides synthesized with only ethylene glycol (EG) as solvent and b NaF and nano metal fluorides synthesized using lactic acid and ethylene glycol as solvent 
of $\mathrm{CaF}_{2}$ is lower than that of $\mathrm{MgF}_{2}$. Hence, $\mathrm{CaF}_{2}$ at $0.5 \mathrm{M}$ was not tested for efficacy against termites. Nonetheless, wood specimens treated with the single sol combination of $\mathrm{MgF}_{2}$ and $\mathrm{CaF}_{2}$ at $0.5 \mathrm{M}$ caused $100 \%$ termite mortality. Treatment with $\mathrm{NaF}$ at $0.1 \mathrm{M}$ also resulted in $100 \%$ mortality (Fig. 1b). Both, $\mathrm{CaF}_{2}$ in lactic acid at $0.8 \mathrm{M}$ and the combination of $\mathrm{CaF}_{2}$ and $\mathrm{MgF}_{2}$ at $0.5 \mathrm{M}$ led to $100 \%$ termite mortality as well. The $100 \%$ termite mortality caused by nano metal fluorides at higher concentrations indicates that the toxicity of nano metal fluorides is the same as that of $\mathrm{NaF}$ and can be compared to nanoboron and nanozinc borate which also led to $100 \%$ termite mortality (Kartal et al. 2009; Mantanis et al. 2014; Tascioglu et al. 2017).

Surprisingly, the specimens treated only with lactic acid also resulted in $100 \%$ termite mortality (Fig. 1b). This suggests that lactic acid might provide resistance similar to that observed for acetylated radiata pine wood exposed to $R$. banyulensis, which also showed $100 \%$ termite mortality (Gascón-Garrido et al. 2013).

From Fig. 2a, it can be seen that the control specimens had significantly higher average mass loss due to termite attack than treated specimens ( $\mathrm{p}$ value $<0.01$ ). For $\mathrm{MgF}_{2}$ and $\mathrm{CaF}_{2}$ treated specimens respectively, mass loss was not affected by treatment concentration. However, $\mathrm{MgF}_{2}$ treated specimens had lower average mass loss compared to $\mathrm{CaF}_{2}$ treated specimens. The combination treatment of $\mathrm{MgF}_{2}$ and $\mathrm{CaF}_{2}(0.5 \mathrm{M})$ had a lower mass loss than $\mathrm{CaF}_{2}$ treatment alone, but a similar average mass loss when compared to the $\mathrm{MgF}_{2}$ treatments at higher concentration of 0.5 and $0.8 \mathrm{M}$. Therefore, the lower concentration of $0.5 \mathrm{M}$ seems to be sufficient to promote antifeedant effect against $C$. formosanus similar to that observed for nanozinc borate (Mantanis et al. 2014).

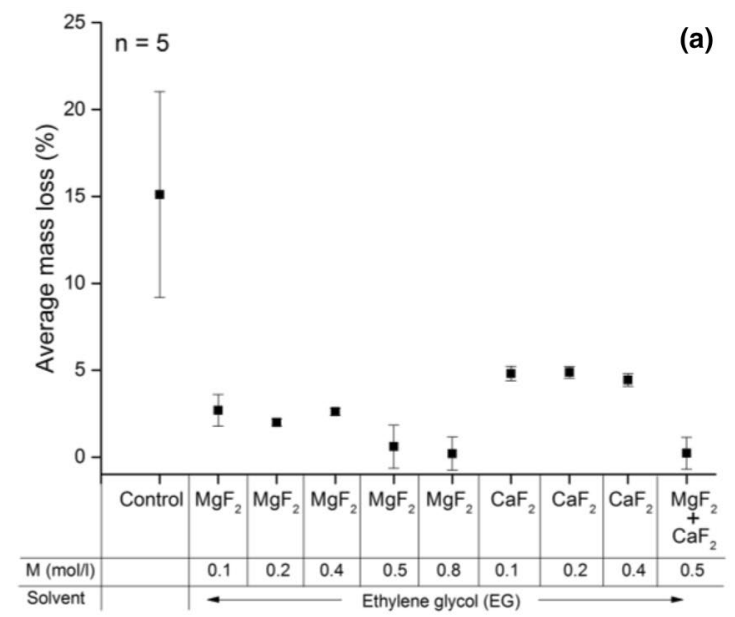

From Fig. 2b, it is observed that the control specimens had significantly higher average mass loss compared to fluoride treated specimens ( $\mathrm{p}$ value $<0.01$ ). Average mass loss in lactic acid treated specimens was not significantly different compared to control specimens ( $p$ value -0.70 ), suggesting that termites consumed lactic acid treated specimens as they consumed control specimens. NaF-treated wood had mass loss less than $2 \%$. Mass loss was even lower for $\mathrm{CaF}_{2}$ (in lactic acid) treatment alone and for the combination treatment of $\mathrm{CaF}_{2}$ (in lactic) and $\mathrm{MgF}_{2}$ (in ethylene glycol), respectively. This is somehow surprising since the freely available fluoride concentration in both, $\mathrm{MgF}_{2}$ and $\mathrm{CaF}_{2}$, due to their lower solubility is significantly lower than in the case of $\mathrm{NaF}$, although the nominal concentration of the latter is lower.

Figure 3 a shows the control specimens had higher visual ratings for damage than wood specimens treated with nano metal fluorides, which corresponds well with losses of mass (Fig. 2a). For both $\mathrm{MgF}_{2}$ and $\mathrm{CaF}_{2}$ treated specimens in the concentration from 0.1 to $0.4 \mathrm{M}$, the average visual assessment was above rating " 3 ". Based on this and according to EN 350 (2016), treated samples would be considered as "not durable". For specimens treated with higher concentrations of $\mathrm{MgF}_{2}(0.5$ and $0.8 \mathrm{M})$, the visual ratings were below "2". Similarly, test specimens treated with the single sol combination of $\mathrm{MgF}_{2}$ and $\mathrm{CaF}_{2}$ showed only minor damage with the average visual rating below " 2 ".

From Fig. 3b, it is observed that all the control specimens had an average visual rating of "4", which was higher than those observed for treated specimens. Specimens treated with only lactic acid had an average visual rating of " 2.5 ", while $\mathrm{NaF}$ and $\mathrm{CaF}_{2}$ (in lactic acid) treated specimens had average visual ratings below " 2 ". Therefore, fluoride treated specimens were less damaged than lactic acid treated

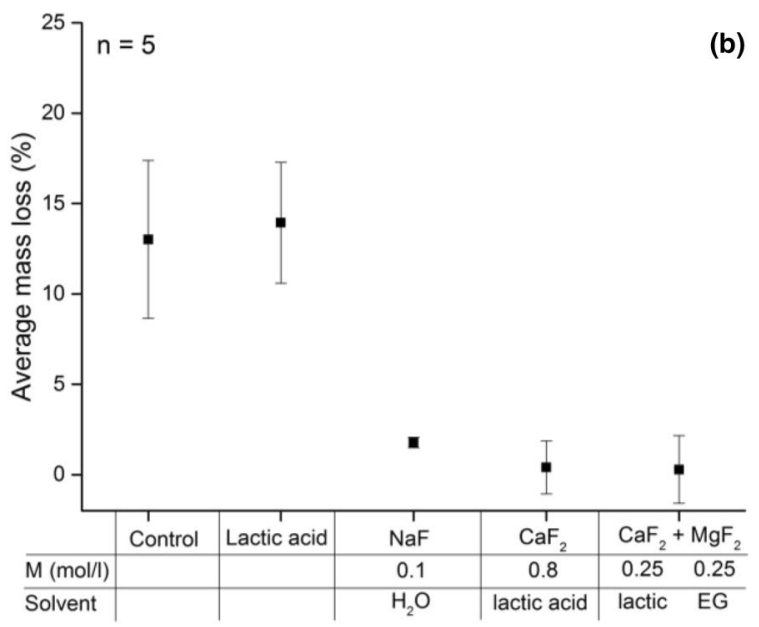

Fig. 2 Average mass loss of specimens a treated with nano metal fluorides synthesized with only ethylene glycol (EG) as solvent and $\mathbf{b} \mathrm{NaF}$ and nano metal fluorides synthesized using lactic acid and ethylene glycol as solvent 

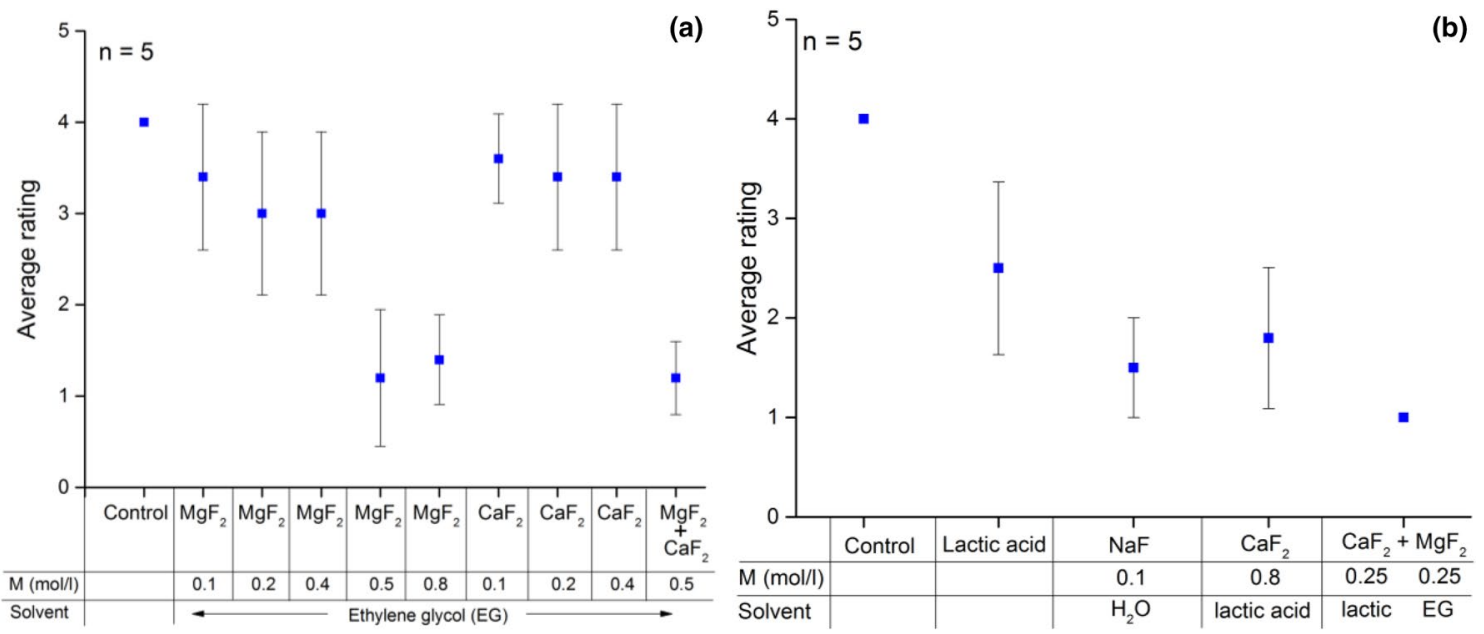

Fig. 3 Visual assessment rating a treated with $\mathrm{NaF}$ and nano metal fluorides synthesized using lactic acid and ethylene glycol (EG) as solvent, b nano metal fluorides synthesized with only ethylene glycol as solvent

specimens. Even though lactic acid treated specimens caused $100 \%$ termite mortality, they were more damaged compared to wood specimens treated with nano metal fluorides at concentrations of 0.5 and $0.8 \mathrm{M}$, which suggests that the effects of lactic acid had to accumulate over time with delayed mortality after the termites had consumed larger amounts of lactic acid treated wood. The delayed toxicity effect might be triggered by the low $\mathrm{pH}$ of lactic acid, which might be too acidic for the protists in the termite gut that are responsible for digesting the cellulose. However, these are unleached specimens and it is likely that lactic acid would be leached out under leaching conditions and thus reduce its toxic effect on the gut microorganisms. Finally, the two-step combination treatment of $\mathrm{CaF}_{2}$ and $\mathrm{MgF}_{2}$ led to even lower visual ratings of " 1 ", which would be considered "durable" according to durability classification in EN 350 (2016).

Nano metal fluoride treated specimens $\left(\mathrm{MgF}_{2}\right.$ and $\left.\mathrm{CaF}_{2}\right)$ performed similar to $\mathrm{NaF}$ treated specimens. Wood specimens treated with $\mathrm{NaF}$ at $0.1 \mathrm{M}$ had a lower rating for visual damage, lower mass loss, and higher termite mortality compared to control specimens. These results show that nano metal fluorides can be suitable alternatives to water soluble $\mathrm{NaF}$. Evaluating the durability of nano- $\mathrm{MgF}_{2}$ and $-\mathrm{CaF}_{2}$ in comparison to $\mathrm{NaF}$, at the first glance, it seems that higher concentrations of the nano- $\mathrm{MF}_{2}$ systems are necessary. However, the opposite is true. The solubility of $\mathrm{NaF}$ is $40 \mathrm{~g} / \mathrm{L}$, while that of $\mathrm{MgF}_{2}(130 \mathrm{mg} / \mathrm{L})$ and of $\mathrm{CaF}_{2}(16 \mathrm{mg} / \mathrm{L})$ is significantly lower (Lide 2003). That means although nominally higher concentrations of $\mathrm{MgF}_{2}$ and $\mathrm{CaF}_{2}$ are needed for resistance against $C$. formosanus, just a very small part of the nanoparticles becomes dissolved, consequently a very low concentration of free fluoride ions is available. Thus, the latter fluorides are evidently more sustainable since the fluoride anions are released over a significantly larger time scale as they are mainly present as insoluble $\mathrm{MF}_{2}$ and only a small part is dissolved in wood specimens depending on moisture conditions.

Even the fact that $\mathrm{MgF}_{2}$-treated specimens performed better than $\mathrm{CaF}_{2}$ with lower average mass loss and lower visual ratings after termite attack by $C$. formosanus is due to the differences in their solubility. With $130 \mathrm{mg} / \mathrm{L}$ solubility of $\mathrm{MgF}_{2}$ in water compared to just $16 \mathrm{mg} / \mathrm{L}$ solubility of $\mathrm{CaF}_{2}$ in water, the same nominal concentration of both sols provides a free fluoride concentration in water being nearly higher by the factor of 10 for $\mathrm{MgF}_{2}$. Surprisingly, the combination of $\mathrm{CaF}_{2}$ and $\mathrm{MgF}_{2}$ has similar effects at a lower concentration of $0.5 \mathrm{M}$ than using either $\mathrm{CaF}_{2}$ or $\mathrm{MgF}_{2}$ alone at a higher concentration of $0.8 \mathrm{M}$. A reasonable explanation might be that not both metal fluorides exist as such in these combined systems but instead $\mathrm{CaMgF}_{4}$ is formed, which has a solubility between that of $\mathrm{CaF}_{2}$ and $\mathrm{MgF}_{2}$ alone. Therefore, the combination provides an increased fluoride concentration compared with the single $\mathrm{MgF}_{2}$ system. Although the formation of $\mathrm{CaMgF}_{4}$ complexes has been reported previously, solubility data is not available for this complex compound (Krahl et al. 2016).

\section{Conclusion}

Previous research has reported that fluoride can be effective at low concentrations against fungi and termites (Gay and Schulz 1965; Freitag and Morrell 2005; Pan et al. 2015). This study shows that specimens treated with nano metal fluorides are less damaged than the severely attacked controls when exposed to termites. In this work, the low water-soluble nano metal fluorides $\mathrm{CaF}_{2}$ and $\mathrm{MgF}_{2}$ alone performed very well, but their combination performed even 
better than $\mathrm{NaF}$ in visual ratings of treated wood specimens. This test was done over a duration of 8 weeks, while the termite resistance test with other nano treatments such as nanoboron and nano zinc borate reported in the literature were done for four weeks or less. Thus, it is expected that nano metal fluoride treated samples provide a longer-term protection compared to other nano formulations. Test specimens in this study were not leached prior to biological testing. In future experiments, leached wood specimens treated with nano metal fluorides have to be tested in comparison to leached $\mathrm{NaF}$ treated specimens. It can be assumed that susceptibility to leaching is significantly reduced with nano metal fluorides compared to NaF. The lower water solubility of $\mathrm{MgF}_{2}$ and $\mathrm{CaF}_{2}$ means that they can be used without fixatives making them more environmentally friendly and sustainable alternatives for wood protection against termites. The results from this study evidently show the potential of low water-soluble nano metal fluorides as effective and sustainable wood preservative formulations against termites.

Acknowledgements Open Access funding provided by Projekt DEAL. We thank Dr. Franziska Emmerling for valuable feedback and structural support, Dr. Alexander Rehmer, Dr. Thoralf Krahl, and Mr. Stefan Mahn for synthesis of $\mathrm{CaF}_{2}$ and $\mathrm{MgF}_{2}$ sols, Mr. Jörg Schlischka for support in sol-gel impregnation into wood, Dr. Ina Stephan, Ms. Kerstin Klutzny and Ms. Yvonne de Laval for support in termite resistance test.

Open Access This article is licensed under a Creative Commons Attribution 4.0 International License, which permits use, sharing, adaptation, distribution and reproduction in any medium or format, as long as you give appropriate credit to the original author(s) and the source, provide a link to the Creative Commons licence, and indicate if changes were made. The images or other third party material in this article are included in the article's Creative Commons licence, unless indicated otherwise in a credit line to the material. If material is not included in the article's Creative Commons licence and your intended use is not permitted by statutory regulation or exceeds the permitted use, you will need to obtain permission directly from the copyright holder. To view a copy of this licence, visit http://creativecommons.org/licenses/by/4.0/.

\section{References}

Bradshaw CJA, Leroy B, Bellard C, Roiz D, Albert C, Fournier A, Barbet-Massin M, Salles JM, Simard F, Courchamp F (2016) Massive yet grossly underestimated global costs of invasive insects. Nat Commun 7:12986. https://doi.org/10.1038/ncomms12986

Buczkowski G, Bertelsmeier C (2017) Invasive termites in a changing climate: a global perspective. Ecol Evol 7:974-985. https://doi. org/10.1002/ece 3.2674

Chouvenc T, Li HF, Austin J et al (2016) Revisiting Coptotermes (Isoptera: Rhinotermitidae): a global taxonomic road map for species validity and distribution of an economically important subterranean termite genus. Syst Entomol 41:299-306. https:// doi.org/10.1111/syen.12157

Civardi C, Schubert M, Fey A, Wick P, Schwarze FWMR (2015) Micronized copper wood preservatives: efficacy of ion, nano, and bulk copper against the brown rot fungus rhodonia placenta. PLoS
One 10(11):e0142578. https://doi.org/10.1371/journal.pone.01425 78

Clausen CA, Kartal SN, Arango RA, Green F (2011) The role of particle size of particulate nano-zinc oxide wood preservatives on termite mortality and leach resistance. Nanoscale Res Lett 6:1-5. https://doi.org/10.1186/1556-276X-6-427

Dhang P (2011) Insecticides as Urban Pollutants. In: Dhang P (ed) Urban pest management: an environmental perspective. CABI, Cambridge, pp 1-18

EN 117 (2012) Wood preservatives - Determination of toxic values against Reticulitermes species (European termites) (Laboratory method). European Committee for Standardization, Brussels

EN 350 (2016) Durability of wood and wood-based products - Testing and classification of the durability to biological agents of wood and wood materials. European Committee for Standardization (CEN), Brussels

Evans P, Matsunaga H, Kiguchi M (2008) Large-scale application of nanotechnology for wood protection. Nat Nanotechnol 3:577. https://doi.org/10.1038/nnano.2008.286

Freitag C, Morrell JJ (2005) Development of threshold values for boron and fluoride in non-soil contact applications. For Prod J 55:97-101

Garlotta D (2001) A literature review of poly(lactic acid). J Polym Environ 9:63-84. https://doi.org/10.1023/A:1020200822435

Gascón-Garrido P, Oliver-Villanueva JV, Ibiza-Palacios MS, Militz H, Mai C, Adamopoulos S (2013) Resistance of wood modified with different technologies against Mediterranean termites (Reticulitermes spp.). Int Biodeterior Biodegrad 82:13-16. https://doi. org/10.1016/j.ibiod.2012.07.024

Gay FJ, Schulz WO (1965) Comparison of two water-soluble wood preservatives against termite attack. Holz Roh- Werkst 23:6-9. https://doi.org/10.1007/bf02619016

Ibáñez CM, Camargo A, Mantero C, Faccio R, Malanga A, Rabinovich M (2019) Effectiveness of micronizing zinc borate to improve its fungicidal properties. BioResources 14:6231-6246. https://doi. org/10.15376/biores.14.3.6231-6246

Imamura Y, Nishimoto K (1986) Resistance of acetylated wood to attack by subterranean termites. Wood Res 72:37-44

Kartal SN, Green F, Clausen CA (2009) Do the unique properties of nanometals affect leachability or efficacy against fungi and termites? Int Biodeterior Biodegrad 63:490-495. https://doi. org/10.1016/j.ibiod.2009.01.007

Kartal SN, Terzi E, Yoshimura T (2019) Performance of fluoride and boron compounds against drywood and subterranean termites and decay and mold fungi. J For Res. https://doi.org/10.1007/s1167 6-019-00939-4

Kemnitz E, Groß U, Rüdiger S, Shekar CS (2003) Amorphous metal fluorides with extraordinary high surface areas. Angew Chemie Int Ed 42(35):4251-4254. https://doi.org/10.1002/anie.200351278

Krahl T, Broßke D, Scheurell K, Lintner B, Kemnitz E (2016) Novel aspects in the chemistry of the non-aqueous fluorolytic sol-gel synthesis of nanoscaled homodisperse $\mathrm{MgF} 2$ sols for antireflective coatings. J Mater Chem C 4:1454-1466. https://doi.org/10.1039/ c5tc03764f

Lide DR (2003) CRC Handbook of Chemistry and Physics, 84th Edition, 2003-2004. Handb Chem Phys. https://doi.org/10.1136/ oem.53.7.504

Lykidis C, De Troya T, Conde M, Galván J, Mantanis G (2018) Termite resistance of beech wood treated with zinc oxide and zinc borate nanocompounds. Wood Mater Sci Eng 13(1):45-49. https://doi. org/10.1080/17480272.2016.1257651

Mahn S, Kemnitz E (2019) Modification of low-molecular polylactic acid by $\mathrm{CaF} 2$ nanoparticles: a new approach to change its material properties. J Appl Polym Sci 136:1-6. https://doi.org/10.1002/ app. 47875 
Mantanis G, Terzi E, Kartal SN, Papadopoulos AN (2014) Evaluation of mold, decay and termite resistance of pine wood treated with zinc- and copper-based nanocompounds. Int Biodeterior Biodegrad 90:140-144. https://doi.org/10.1016/j.ibiod.2014.02.010

Pan C, Wang C (2015) Sodium fluoride for protection of wood against field populations of Subterranean Termites. J Econ Entomol 108:2121-2124. https://doi.org/10.1093/jee/tov175

Pan C, Ruan G, Chen H, Zhang D (2015) Toxicity of sodium fluoride to subterranean termites and leachability as a wood preservative. Eur J Wood Prod 73:97-102. https://doi.org/10.1007/s0010 7-014-0849-x

Pimentel D, Zuniga R, Morrison D (2005) Update on the environmental and economic costs associated with alien-invasive species in the United States. Ecol Econ 52:273-288. https://doi.org/10.1016/j. ecolecon.2004.10.002

Roark RC (1926) Fluorides vs. fluosilicates as insecticides. Science 63:431-432

Sun L, Chow LC (2008) Preparation and properties of nano-sized calcium fluoride for dental applications. Dent Mater 24:111-116. https://doi.org/10.1016/j.dental.2007.03.003

Taghiyari HR (2015) Future prospects of wood preservation with nanotechnology. Lignocellulose 4:1-3

Tascioglu C, Umemura K, Kusuma SS, Yoshimura T (2017) Potential utilization of sodium fluoride $(\mathrm{NaF})$ as a biocide in particleboard production. J Wood Sci 63:652-657. https://doi.org/10.1007/ s10086-017-1654-z

Terzi E, Kartal SN, Yilgör N, Rautkari L, Yoshimura T (2016) Role of various nano-particles in prevention of fungal decay, mold growth and termite attack in wood, and their effect on weathering properties and water repellency. Int Biodeterior Biodegrad 107:77-87. https://doi.org/10.1016/j.ibiod.2015.11.010

Usmani SM, Stephan I, Hübert T, Kemnitz E (2018) Nano metal fluorides for wood protection against fungi. ACS Appl Nano Mater 1(4):1444-1449. https://doi.org/10.1021/acsanm.8b00144

Weston DP, Holmes RW, You J, Lydy MJ (2005) Aquatic toxicity due to residential use of pyrethroid insecticides. Environ Sci Technol 39:9778-9784. https://doi.org/10.1021/es0506354

Xie Y, Du Q, Huang Q, Lei C (2013) Evaluation of formic acid toxicity to subterranean termite, Reticulitermes chinensis Snyder. Sociobiology 60:453-458. https://doi.org/10.13102/sociobiolo gy.v60i4.453-458

Publisher's Note Springer Nature remains neutral with regard to jurisdictional claims in published maps and institutional affiliations. 